This item was submitted to Loughborough's Research Repository by the author.

Items in Figshare are protected by copyright, with all rights reserved, unless otherwise indicated.

\title{
The importance of vigorous-intensity, leisure-time physical activity in reducing cardiovascular disease mortality risk in the obese
}

\section{PLEASE CITE THE PUBLISHED VERSION}

https://doi.org/10.1016/j.mayocp.2018.01.016

\section{PUBLISHER}

Elsevier (C) Mayo Foundation for Medical Education and Research

VERSION

AM (Accepted Manuscript)

\section{PUBLISHER STATEMENT}

This work is made available according to the conditions of the Creative Commons Attribution-NonCommercialNoDerivatives 4.0 International (CC BY-NC-ND 4.0) licence. Full details of this licence are available at: https://creativecommons.org/licenses/by-nc-nd/4.0/

\section{LICENCE}

CC BY-NC-ND 4.0

\section{REPOSITORY RECORD}

O'Donovan, Gary, Emmanuel Stamatakis, David J. Stensel, and Mark Hamer. 2019. "The Importance of Vigorous-intensity, Leisure-time Physical Activity in Reducing Cardiovascular Disease Mortality Risk in the Obese". figshare. https://hdl.handle.net/2134/28062. 


\section{Mayo Clinic Proceedings}

\section{The importance of vigorous-intensity leisure-time physical activity in reducing cardiovascular disease mortality risk in the obese}

\begin{tabular}{|r|l|}
\hline Journal: & Mayo Clinic Proceedings \\
\hline Manuscript ID & 2017-1202.R1 \\
\hline Manuscript Categories: & Original Article \\
\hline Date Submitted by the Author: & n/a \\
\hline Keyword: List of Authors: & $\begin{array}{l}\text { O'Donovan, Gary; Loughborough University, School of Sport, Exercise and } \\
\text { Health Sciences } \\
\text { Stamatakis, Emmanuel; University of Sydney Sydney Medical School, } \\
\text { School of Public Health } \\
\text { Stensel, David; Loughborough University, School of Sport, Exercise and } \\
\text { Health Sciences } \\
\text { Hamer, Mark; Loughborough University, school sport exercise health } \\
\text { sciences; University College London Medical School, }\end{array}$ \\
\hline & Cohort studies, Exercise, Primary prevention \\
\hline
\end{tabular}

\section{SCHOLARONE ${ }^{\text {TW }}$}

Manuscripts 
2

3

4

5

6

7

8

1 The importance of vigorous-intensity leisure-time physical activity in reducing

2 cardiovascular disease mortality risk in the obese

3

4 Running head: Vigorous activity, obesity and mortality risk

6 Gary O’Donovan, Ph.D. ${ }^{1}$ Emmanuel Stamatakis, Ph.D. ${ }^{2,3}$ David J Stensel, Ph.D. ${ }^{1}$ and Mark

7 Hamer, Ph.D. ${ }^{1,3}$

$9{ }^{1}$ School of Sport, Exercise and Health Sciences, National Centre for Sport \& Exercise

10 Medicine - East Midlands, Loughborough University, Loughborough LE11 3TU, United

11 Kingdom. ${ }^{2}$ Charles Perkins Centre, Prevention Research Collaboration, School of Public

12 Health, University of Sydney, Sydney, Australia. ${ }^{3}$ Department of Epidemiology and Public

13 Health, University College London, London WC1E 6BT, United Kingdom.

15 Correspondence: Dr Gary O’Donovan, National Centre for Sport \& Exercise Medicine - East

16 Midlands, Loughborough University, Loughborough LE11 3TU, United Kingdom. Phone:

$17 \quad+44(0) 1509226$ 302. Email: G.ODonovan@1boro.ac.uk

19 Conflicts of interest: The authors have nothing to disclose.

21 Sources of support: O’Donovan, Stensel and Hamer were supported by the National Institute

22 for Health Research Leicester Biomedical Research Centre, which is a partnership between

23 University Hospitals of Leicester NHS Trust, Loughborough University, and University of

24 Leicester. 


\section{Abstract \\ 26}

27 Objective: To investigate the role of vigorous-intensity leisure-time physical activity in

28 reducing cardiovascular disease (CVD) mortality risk in the obese.

29 Methods: Trained interviewers assessed physical activity and body mass index (BMI) in

3059,005 adult participants $(57 \pm 12$ years of age $[$ mean $\pm \mathrm{SD}] ; 46.5 \%$ male) in the household-

31 based surveillance studies, Health Survey for England and Scottish Health Survey. Mortality

32 was ascertained from death certificates. Data were collected from January 1994 to March

33 2011. Cox proportional hazards models were adjusted for age, sex, smoking habit, total

34 physical activity, longstanding illness, prevalent CVD, and occupation.

35 Results: There were 2,302 CVD deaths during 532,251 person-years of follow-up ( $9 \pm 4$

36 years). Some $25 \%$ of participants were categorized as obese $\left(B M I \geq 30 \mathrm{~kg} \cdot \mathrm{m}^{-2}\right)$. Leisure-time

37 physical activity was inversely associated and BMI was positively associated with CVD

38 mortality. Compared to those who reported meeting physical activity guidelines, including

39 some vigorous-intensity physical activity, and who had a normal BMI $\left(18.5-24.9 \mathrm{~kg} \cdot \mathrm{m}^{-2}\right)$

40 (reference group), CVD mortality hazard ratio was not significantly different in the obese

41 who also reported meeting physical activity guidelines, including some vigorous-intensity

42 physical activities $(1.25 ; 95 \%$ confidence interval: $0.50,3.12)$. Compared to the reference

43 group, CVD mortality hazard ratio was more than twofold in the obese who reported meeting

44 physical activity guidelines, including only moderate-intensity physical activities $(2.52 ; 95 \%$

45 CI: $1.15,2.53)$.

46 Conclusion: This large, statistically powerful study suggests that vigorous-intensity leisure-

47 time physical activity is important in reducing CVD mortality risk in the obese. 

48 Abbreviations
49
$50 \quad \mathrm{BMI}=$ body mass index
$51 \mathrm{CI}=$ confidence interval
$52 \quad \mathrm{CVD}=$ cardiovascular disease
$53 \mathrm{HR}=$ hazard ratio
54 HSE = Health Survey for England
$55 \quad \mathrm{ICD}=$ International Classification of Disease
$56 \quad$ MET $=$ Metabolic equivalent
$57 \quad$ SHS $=$ Scottish Health Survey 


\section{Introduction}

60 Compared to normal weight adults, cardiovascular disease (CVD) mortality risk is greater in

61 overweight adults and greater still in obese adults (1). The American College of Sports

62 Medicine and the American Heart Association recommend physical activity in the primary

63 prevention of morbidity and mortality in the general population (2); nonetheless, the

64 relationship between physical activity and CVD mortality in the obese is unclear. The inverse

65 association between physical activity and CVD mortality risk in the general population is

66 independent of body mass index (BMI) (3); however, few studies have been large enough to

67 investigate the association between physical activity and CVD mortality risk in the obese per

68 se (4). Compared to being inactive, any participation in vigorous-intensity physical activity is

69 associated with lower CVD mortality risk in the general population (3). Therefore, the

70 objective of the present study was to investigate the role of vigorous-intensity physical

71 activity in reducing CVD mortality risk in the obese using a pooled analysis of 11 population-

72 based cohorts. 


\section{$73 \quad$ Methods}

\section{4}

75

Participants

76

77 The methods used in Health Survey for England (HSE) and Scottish Health Survey (SHS) are

78 consistent and are described in detail elsewhere (5,6). Briefly, HSE and SHS are household-

79 based surveillance surveys in which households are selected using a multistage, stratified

80 probability design in order to be representative of the target populations of each country.

81 Stratification is based on geographical areas, not individual characteristics: postcode (zip

82 code) sectors are selected at the first stage and household addresses are selected at the second

83 stage. Participants in the present study were from surveys conducted in 1994 (HSE only),

841995 (SHS only), 1997 (HSE only), 1998 (HSE and SHS), 1999 (HSE only), 2003 (HSE and

85 SHS), 2004 (HSE only), 2006 (HSE only), and 2008 (HSE only). Participants aged 40 years

86 or older were included in the present study because it was deemed likely that congenital

87 abnormalities would be responsible for cardiac events in young individuals and lifestyle

88 would be responsible for such events in middle-aged and older adults (7). Data were collected

89 from January 1994 to March 2011. Local research ethics committees approved each survey

90 and participants gave written informed consent.

91

92 Physical activity

93

94 Trained interviewers asked about physical activity. Physical activity was assessed using an

95 established questionnaire that is described elsewhere (8). Briefly, the interviewer used the

96 questionnaire to enquire about the following aspects of the respondent's physical activity in

97 the four weeks prior to the interview: frequency and duration of participation in domestic 
98 physical activity ('light' and 'heavy' housework, gardening and 'do-it-yourself'); frequency,

99 duration and pace of walking (slow, average, brisk or fast); frequency, duration and perceived

100 intensity of participation in sports and exercise using a prompt card showing 10 main

101 groupings, including cycling, swimming, jogging/running, football, rugby, tennis and squash

102 (six open entries could also be recorded). The validity (9) and reliability (10) of the physical

103 activity questionnaire are described elsewhere. A compendium was used to identify physical

104 activity intensities according to metabolic equivalents (METs), where one MET represents

105 resting energy expenditure (11). Light-intensity activities were of 1.5-2.9 METs, moderate-

106 intensity activities were of 3.0-5.9 METs, and vigorous-intensity activities were of $\geq 6.0$

107 METs. A MET-hour was computed by multiplying the MET score of an activity by the time

108 (in hours). Total physical activity was computed by summing the MET-hours of all light-,

109 moderate-, and vigorous-intensity activities. Only leisure-time physical activities were

110 included in the present analysis, not occupational and routine domestic activities.

111

112 Obesity

113

114 Trained interviewers measured weight and height (6), and BMI was expressed as weight in

115 kilograms divided by height in meters squared. Overweight was defined as a BMI of $25-<30$

$116 \mathrm{~kg} \cdot \mathrm{m}^{-2}$ and obese as a BMI of $\geq 30 \mathrm{~kg} \cdot \mathrm{m}^{-2}(12)$. Trained and qualified nurses measured waist

117 circumference at the midpoint of the iliac crest and costal margin (lower rib). Obesity was

118 defined as a waist circumference $>102 \mathrm{~cm}$ in men and $>88 \mathrm{~cm}$ in women (13). 


\section{Covariates}

120

121 The trained interviewers also asked about age, sex, smoking habit, longstanding illness,

122 cardiovascular disease, occupation, and ethnicity. Socioeconomic status was determined from

123 participants' occupations using the four-group version of the Registrar General's

124 classification: professional and managerial occupations; skilled, non-manual occupations;

125 skilled manual occupations; and, routine and manual occupations.

Mortality follow-up

128

129 The British National Health Service Central Registry flagged participants. Data for survivors

130 were censored to the end of 2009 (SHS) or the first quarter of 2011 (HSE). Diagnoses for the

131 primary cause of death were based on the International Classification of Diseases, Ninth

132 (ICD-9) and Tenth (ICD-10) Revisions. Codes corresponding to CVD mortality were 390-

133459 for ICD-9 and I01-I99 for ICD-10.

134

135

Statistical analysis

136

137 Cox proportional hazards models were used to estimate the associations between physical

138 activity, obesity and CVD mortality risk. In keeping with prevailing guidelines (2), exposure

139 to physical activity was defined as at least 150 minutes per week of moderate-intensity

140 physical activity, at least 75 minutes per week of vigorous-intensity activity, or equivalent

141 combinations. We further distinguished between the physically active who reported taking

142 part in vigorous-intensity activity and those who did not in order to investigate the role of

143 physical activity intensity in reducing CVD mortality risk. The proportional hazards 
144 assumption was examined by comparing the cumulative hazard plots grouped on exposure;

145 and, no appreciable violations were noted. Calendar time (months) was the timescale. Data

146 from the underweight (BMI $<18.5 \mathrm{~kg} \cdot \mathrm{m}^{-2}$ ) and those who died during the first 24 months of

147 follow-up were not used. Analyses were adjusted for age and sex (Model 1) and further

148 adjusted for smoking habit, total physical activity, longstanding illness, prevalent CVD, and

149 occupation (Model 2). The associations between physical activity, obesity and CVD mortality

150 risk in those who reported never smoking was investigated in a sensitivity analysis. All

151 analyses were performed using SPSS version 22 (IBM Inc.). 


\section{Results}

153

154 Supplemental Figure 1 shows the sample selection; 59,005 participants in HSE and SHS were

155 included in the present study. Table 1 shows participants' characteristics at baseline

156 according to BMI. The average age was 57 years and was significantly different in the

157 normal, overweight, and obese groups. Some $47 \%$ of participants were men and the

158 proportions of men were lower in the normal BMI and obese groups. The average leisure-

159 time physical activity level was higher in those with a normal BMI but there were

160 considerable differences within each BMI group. The proportion of current smokers was

161 higher in those with a normal BMI than those who were overweight or obese. The proportion

162 in professional and managerial occupations was lower and the proportion in semi-skilled and

163 unskilled manual occupations was higher in the obese group than the other groups. The

164 proportions with longstanding illness and prevalent CVD were also higher in the obese group

165 than the other groups. The proportion of CVD deaths during follow-up was $3.6 \%$ in the

166 normal, $4.0 \%$ in the overweight, and $4.1 \%$ in the obese BMI groups. Supplemental Table 1

167 shows physical activity levels according to prevailing physical activity guidelines. Moderate-

168 to vigorous-intensity physical activity was $327 \pm 354 \mathrm{~min} \cdot \mathrm{wk}^{-1}$ (mean $\pm \mathrm{SD}$ ) in those who

169 reported meeting the guidelines including some vigorous-intensity activity and $404 \pm 394$

$170 \mathrm{~min} \cdot \mathrm{wk}^{-1}$ in those who reported meeting the guidelines including only moderate-intensity

171 activity. Total physical activity was $50 \pm 43 \mathrm{MET}-\mathrm{hr}^{\cdot} \mathrm{wk}^{-1}$ in those who reported meeting the

172 guidelines including some vigorous-intensity activity and $48 \pm 47 \mathrm{MET}-\mathrm{hr}^{\cdot} \cdot \mathrm{wk}^{-1}$ in those who

173 reported meeting the guidelines including only moderate-intensity activity.

175 Table 2 shows mean waist girth values in men and women according to BMI and physical

176 activity. Statistical significance was investigated in the obese. Compared to obese men who 
177 reported meeting physical activity guidelines, including some vigorous-intensity physical

178 activity (reference group), waist girth was not significantly different in obese men who

179 reported meeting physical activity guidelines, including only moderate-intensity physical

180 activities (mean difference: $1.4 \mathrm{~cm}$; 95\% confidence interval, CI: $-0.4,3.2 ; p=.54$ ). Compared

181 to the reference group, waist girth was not significantly different in obese men who were

182 active, but did not meet physical activity guidelines (mean difference: $1.1 \mathrm{~cm} ; 95 \% \mathrm{CI}:-0.2$,

$1832.5 ; p=0.36)$. Compared to the reference group, waist girth was significantly different in

184 obese men who were inactive (mean difference: $3.2 \mathrm{~cm} ; 95 \%$ CI: 2.0, 4.5; $p<.001$ ). Compared

185 to obese women who reported meeting physical activity guidelines, including some vigorous-

186 intensity physical activity (reference group), waist girth was not significantly different in

187 obese women who reported meeting physical activity guidelines, including only moderate-

188 intensity physical activities (mean difference: $1.2 \mathrm{~cm} ; 95 \% \mathrm{CI}:-1.0,3.4 ; p=.99$ ). Compared to

189 the reference group, waist girth was not significantly different in obese women who were

190 active, but did not meet physical activity guidelines (mean difference: $0.8 \mathrm{~cm}$; $95 \%$ CI: -0.9 ,

$1912.6 ; p=0.99)$. Compared to the reference group, waist girth was significantly different in

192 obese women who were inactive (mean difference: $2.9 \mathrm{~cm} ; 95 \% \mathrm{CI}: 1.2,4.5 ; p<.001$ ).

193 Supplemental Table 2 shows that the correlation between waist girth and BMI was .85 to .86

194 in men and women of different physical activity levels.

196 There were 2,302 CVD deaths during 532,251 person-years of follow-up (9 \pm 4 years). Table 3

197 shows the associations between BMI and CVD mortality. Compared to those with a normal

198 BMI (reference group), the fully-adjusted hazard ratio for CVD mortality was not

199 significantly different in the overweight (hazard ratio, HR: 0.97; 95\% CI: 0.87, 1.07), but was

200 higher and significantly different in the obese (HR: 1.23; 95\% CI: 1.10, 1.37). Waist girth

201 was measured in 45,259 participants and the fully-adjusted hazard ratio for CVD mortality 
202 was $1.18(95 \%$ CI: $1.07,1.29)$ in the obese compared to the non-obese. Compared to those

203 who were willing to have their waist girth measured, those who were unwilling were younger 204 (57.7 vs. 56.7 years, $p<.001)$, were more likely to be women ( 53.2 vs. $54.4 \%, p=.007)$, were

205 less physically active (86 vs. 59 minutes per week of moderate- and vigorous-intensity

206 physical activity, $p<.001)$, and were of higher BMI (27.5 vs. $\left.27.7 \mathrm{~kg} \cdot \mathrm{m}^{-2}, p<.001\right)$.

207

208 Table 4 shows the associations between physical activity, BMI, and CVD mortality.

209 Compared to those who reported meeting physical activity guidelines and who had a normal

210 BMI (reference group), the fully-adjusted hazard ratio for CVD mortality was not

211 significantly different in the overweight (HR: 1.41; 95\% CI: $0.94,2.10)$ or the obese (HR:

$2121.41 ; 95 \%$ CI: 0.84, 2.38) who also reported meeting physical activity guidelines. Compared

213 to the reference group, the full-adjusted hazard ratio for CVD mortality was not significantly

214 different in the overweight who reported doing less than the recommended amounts of

215 leisure-time physical activity (HR: 1.34; 95\% CI: 0.92, 1.95), but was higher and

216 significantly different in the obese who reported doing less than the recommended amounts

217 of leisure-time physical activity (HR: 1.84; 95\% CI: 1.21, 2.81). Compared to the reference

218 group, the fully-adjusted hazard ratio for CVD mortality was around twofold in those who

219 reported no leisure-time physical activity per week, including those with a normal BMI, the

220 overweight, and the obese. Supplemental Table 3 shows that the associations between

221 physical activity, BMI, and CVD mortality were similar in men and women. Supplemental

222 Table 4 shows that the associations between physical activity, obesity and CVD mortality risk

223 were also similar in those who reported never smoking.

224

225 Table 5 shows the associations between leisure-time physical activity, BMI, and CVD

226 mortality in the physically active who reported taking part in vigorous-intensity activity and 
227 those who did not. Compared to those who reported meeting physical activity guidelines,

228 including some vigorous-intensity physical activity, and who had a normal BMI (reference

229 group), the fully-adjusted hazard ratio for CVD mortality was not significantly different in

230 the overweight (HR: $1.85 ; 95 \%$ CI: $0.92,3.70$ ) or the obese (HR: $1.25 ; 95 \%$ CI: $0.50,3.12$ )

231 who also reported meeting physical activity guidelines, including some vigorous-intensity

232 physical activity. Compared to the reference group, the fully-adjusted hazard ratio for CVD

233 mortality was not significantly different in those with a normal BMI (HR: $1.45 ; 95 \%$ CI:

$2340.70,3.01)$ or the overweight (HR: 1.70; 95\% CI: 0.86, 3.37) who reported meeting physical

235 activity guidelines, including only moderate-intensity physical activities. Compared to the

236 reference group, the fully-adjusted hazard ratio for CVD mortality was more than twofold in

237 the obese who reported meeting physical activity guidelines, including only moderate-

238 intensity physical activities (HR: 2.52; 95\% CI: 1.15, 2.53). 


\section{Discussion}

240

241 The objective of this study was to investigate the role of vigorous-intensity leisure-time

242 physical activity in reducing CVD mortality risk in the obese. There were two main findings.

243 First, in comparison to those who reported meeting prevailing physical activity guidelines,

244 including some vigorous-intensity activity, and who had a normal BMI (reference group),

245 CVD mortality risk was not significantly different in the obese who also reported meeting

246 prevailing physical activity guidelines, including some vigorous-intensity activity. Second, in

247 comparison with the reference group, CVD mortality risk was increased more than twofold in

248 the obese who reported meeting physical activity guidelines, including only moderate-

249 intensity physical activities. These findings indicate the importance of vigorous-intensity

250 leisure-time physical activity in reducing CVD mortality risk in the obese.

251

252 Few investigators have reported the joint association between physical activity and

253 overweight and obesity with mortality. Hu and colleagues (4) reported that, compared to

254 those who were 'moderately' or 'highly' active and who had a BMI $<30 \mathrm{~kg} \cdot \mathrm{m}^{-2}, \mathrm{CVD}$

255 mortality hazard ratio was 2.09 (95\% CI: 1.68, 2.59) in those who were inactive and who had

256 a BMI $\geq 30 \mathrm{~kg} \cdot \mathrm{m}^{-2}$ (physical activity was 'moderate' in those who reported moderate or high

257 levels of either occupational or leisure-time physical activity; physical activity was 'high' in

258 those who reported moderate or high levels of both occupational and leisure-time physical

259 activity). Leitzman and colleagues (3) reported that, compared to the inactive who had a BMI

$260 \geq 25 \mathrm{~kg} \cdot \mathrm{m}^{-2}$, all-cause mortality hazard ratio was 0.60 (95\% CI: $\left.0.54,0.66\right)$ in those who

261 reported taking part in the recommended amount of moderate-intensity activity and who had

262 a BMI $\geq 25 \mathrm{~kg} \cdot \mathrm{m}^{-2}$, and $0.58(95 \% \mathrm{CI}: 0.52,0.65)$ in those who reported taking part in the

263 recommended amount of vigorous-intensity activity and who had a BMI $\geq 25 \mathrm{~kg} \cdot \mathrm{m}^{-2}$ (the 
264 recommended amount of moderate activity was equivalent to around 30 minutes on most

265 days of the week; the recommended amount of vigorous activity was at least 20 minutes on

266 three days of the week). Leitzman and colleagues (13) did not report the association between

267 physical activity and all-cause mortality in the obese per se. Moholdt and colleagues (14)

268 reported that physical activity was associated with reduced risk of mortality in overweight

269 and obese adults with coronary heart disease. It is biologically plausible that physical activity

270 reduces CVD mortality risk in the overweight and obese because exercise training improves a

271 number of CVD risk factors independent of weight loss $(15,16)$. For example, 24 weeks of

272 aerobic exercise training improved 10 of 11 lipoprotein variables in overweight and obese

273 adults with mild-to-moderate dyslipidemia who were counseled to maintain body weight

274 (17).

275

276 Compared to normal weight adults (BMI $18.5-<25 \mathrm{~kg} \cdot \mathrm{m}^{-2}$ ), CVD mortality hazard ratio is

$2771.22\left(95 \%\right.$ CI: 1.20, 1.24) in overweight adults (BMI $\left.25-<30 \mathrm{~kg} \cdot \mathrm{m}^{-2}\right)(1)$. For BMI over 25

$278 \mathrm{~kg} \cdot \mathrm{m}^{-2}$, the CVD mortality hazard ratio per $5 \mathrm{~kg} \cdot \mathrm{m}^{-2}$ higher BMI is $1.49(95 \% \mathrm{CI}: 1.45,1.53)$

279 (1). It is alarming therefore that, if post 2000 BMI trends continue, there is virtually zero

280 probability of meeting the World Health Organisation target of halting by 2025 the rise in

281 obesity at its 2010 levels (18). Physical activity improves cardiorespiratory fitness (19) and it

282 has been consistently shown that moderate to high levels of fitness attenuate, if not negate,

283 the association between obesity and cardiovascular disease (16). This concept is known as the

284 fat-but-fit paradigm and is present in one fifth of obese individuals (16). Physical inactivity

285 cost global healthcare systems at least US\$54 billion in 2013 (20) and policymakers have

286 been urged to take physical inactivity seriously (21). We agree with those who would have

287 policies to increase physical activity and cardiorespiratory fitness $(16,19,22)$. Vigorous-

288 intensity exercise increases cardiorespiratory fitness more than the same amount of moderate- 
289 intensity exercise (19); And, there are two reasons to think that vigorous-intensity physical

290 activity was particularly important in the present study. First, total physical activity was

291 similar in participants who reported meeting the guidelines including some vigorous-intensity

292 activity and in participants who reported meeting the guidelines including only moderate-

293 intensity activity. Second, the reduction in CVD mortality risk in obese participants who

294 reported meeting the guidelines including some vigorous-intensity activity was independent

295 of total physical activity. Waist girth was not significantly different in obese men and women

296 who took part in vigorous-intensity activity and those who took part in only moderate-

297 intensity activity; however, magnetic resonance imaging and spectroscopy suggest that

298 visceral fat and liver fat are lower in men who are fat, fit and vigorously active (23).

299

300 The present study has some limitations. A causal relationship cannot be inferred from an

301 observational study. The possibility of reverse causation cannot be discounted, where those

302 with underlying disease are less likely to be physically active; however, data from the

303 underweight and those who died during the first 24 months of follow-up were not used; and,

304 the hazard ratios were adjusted for longstanding illness and prevalent CVD to address the

305 notion of reverse causation. Physical activity was self-reported; however, questionnaires are

306 still regarded as the mainstay of established surveillance studies like HSE and SHS (24). 


\section{Conclusion}

308

309 Few studies are large enough to investigate the joint associations of physical activity and

310 obesity with CVD mortality. This large, statistically powerful study suggests that vigorous-

311 intensity leisure-time physical activity is important in reducing CVD mortality risk in the 312 obese. 


\section{Acknowledgements \\ 314 \\ 315 O’Donovan, Stensel and Hamer were supported by the National Institute for Health Research \\ 316 Leicester Biomedical Research Centre, which is a partnership between University Hospitals \\ 317 of Leicester NHS Trust, Loughborough University, and University of Leicester. This work \\ 318 received no specific funding. The authors have no conflicts of interest. O'Donovan conceived \\ 319 the study and drafted the manuscript. Stamatakis acquired and harmonized the dataset. Hamer \\ 320 carried out the statistical analysis, had full access to the data, and takes responsibility for the \\ 321 integrity and accuracy of the results. All authors contributed to the critical revision of the \\ 322 manuscript.}

323

324 Conflicts of Interest

325

326 The authors have nothing to declare. 
327

328

329

330

331

332

333

334

335

336

337

338

339

340

341

342

343

344

345

346

347

348

349

350

351

\section{References}

1. Global BMI Mortality Collaboration, Di Angelantonio E, Bhupathiraju Sh N, Wormser D, Gao P, Kaptoge S et al. Body-mass index and all-cause mortality: individual-participant-data meta-analysis of 239 prospective studies in four continents. Lancet 2016;388(10046):776-86.

2. Haskell WL, Lee IM, Pate RR, Powell KE, Blair SN, Franklin BA et al. Physical activity and public health: updated recommendation for adults from the American College of Sports Medicine and the American Heart Association. Circulation 2007;116(9):1081-93.

3. Leitzmann MF, Park Y, Blair A, Ballard-Barbash R, Mouw T, Hollenbeck AR et al. Physical activity recommendations and decreased risk of mortality. Arch Intern Med 2007;167(22):2453-60.

4. Hu G, Tuomilehto J, Silventoinen K, Barengo NC, Peltonen M, Jousilahti P. The effects of physical activity and body mass index on cardiovascular, cancer and allcause mortality among 47212 middle-aged Finnish men and women. Int J Obes (Lond) 2005;29(8):894-902.

5. Craig R, Deverill C, Pickering K, Prescott A. Methodology and Response. In: Bromley C, Sproston K, Shelton N, editors. The Scottish Health Survey 2003 Volume 4: Technical Report. Edinburgh: Crown, 2005:1-48.

6. $\quad$ Craig R, Mindell J, Hirani V, editors Health Survey for England 2008, Volume 2: Methods and documentation. London: National Centre for Social Research, 2010.

7. Thompson PD, Franklin BA, Balady GJ, Blair SN, Corrado D, Estes NA, 3rd et al. Exercise and acute cardiovascular events placing the risks into perspective: a scientific statement from the American Heart Association Council on Nutrition, 
352 Physical Activity, and Metabolism and the Council on Clinical Cardiology.

$353 \quad$ Circulation 2007;115(17):2358-68.

354 8. Stamatakis E, Hillsdon M, Primatesta P. Domestic physical activity in relationship to 355 multiple CVD risk factors. Am J Prev Med 2007;32(4):320-327.

$3569 . \quad$ Scholes S, Coombs N, Pedisic Z, Mindell JS, Bauman A, Rowlands AV et al. Age-

10. Joint Health Surveys Unit. Health Survey for England Physical Activity Validation

Study: substantive report. Leeds: Information Centre for health and social care. ,

11. Ainsworth BE, Haskell WL, Herrmann SD, Meckes N, Bassett DR, Jr., Tudor-Locke C et al. 2011 Compendium of Physical Activities: a second update of codes and MET values. Med Sci Sports Exerc 2011;43(8):1575-81.

12. World Health Organisation. Obesity and overweight. Fact sheet No 311. Geneva: WHO, 2016.

13. Expert Panel on the Identification Evaluation and Treatment of Overweight in Adults. obesity in adults: executive summary. Expert Panel on the Identification, Evaluation, and Treatment of Overweight in Adults. Am J Clin Nutr 1998;68(4):899-917.

14. Moholdt T, Lavie CJ, Nauman J. Interaction of Physical Activity and Body Mass Index on Mortality in Coronary Heart Disease: Data from the Nord-Trondelag Health Study. Am J Med 2017;130(8):949-957.

15. Hamer M, O'Donovan G. Cardiorespiratory fitness and metabolic risk factors in obesity. Curr Opin Lipidol 2010;21(1):1-7. 
377 16. Ortega FB, Lavie CJ, Blair SN. Obesity and Cardiovascular Disease. Circ Res

$378 \quad 2016 ; 118(11): 1752-70$.

379 17. Kraus WE, Houmard JA, Duscha BD, Knetzger KJ, Wharton MB, McCartney JS et

380 al. Effects of the amount and intensity of exercise on plasma lipoproteins. N Engl J

$381 \quad$ Med 2002;347(19):1483-92.

382 18. NCD Risk Factor Collaboration. Trends in adult body-mass index in 200 countries

383 from 1975 to 2014: a pooled analysis of 1698 population-based measurement studies

384 with 19.2 million participants. Lancet 2016;387(10026):1377-96.

385 19. Ross R, Blair SN, Arena R, Church TS, Despres JP, Franklin BA et al. Importance of

386 Assessing Cardiorespiratory Fitness in Clinical Practice: A Case for Fitness as a

387 Clinical Vital Sign: A Scientific Statement From the American Heart Association.

$388 \quad$ Circulation 2016;134(24):e653-e699.

389 20. Ding D, Lawson KD, Kolbe-Alexander TL, Finkelstein EA, Katzmarzyk PT, van

390 Mechelen W et al. The economic burden of physical inactivity: a global analysis of

391 major non-communicable diseases. Lancet 2016;388(10051):1311-24.

392 21. Das P, Horton R. Physical activity-time to take it seriously and regularly. Lancet $393 \quad 2016 ; 388(10051): 1254-5$.

394 22. Bouchard C, Blair SN, Katzmarzyk PT. Less Sitting, More Physical Activity, or 395 Higher Fitness? Mayo Clinic proceedings 2015;90(11):1533-40.

396 23. O'Donovan G, Thomas EL, McCarthy JP, Fitzpatrick J, Durighel G, Mehta S et al. Fat 397 distribution in men of different waist girth, fitness level and exercise habit. Int J Obes 398 (Lond) 2009;33(12):1356-62.

399 24. Pedisic Z, Bauman A. Accelerometer-based measures in physical activity $400 \quad$ surveillance: current practices and issues. Br J Sports Med 2015;49(4):219-23. 
Table 1. Participants' characteristics at baseline according to body mass index ${ }^{\mathrm{a}}$

\begin{tabular}{lccc}
\hline & & Body mass index (n) & \\
\cline { 2 - 3 } & Normal & Overweight $(25,602)$ & Obese \\
& $(18,401)$ & & $(15,002)$ \\
\hline Age, years & $56.3 \pm 12.3$ & $57.9 \pm 11.8$ & $57.8 \pm 11.2$ \\
Men, \% & 39 & 53 & 44 \\
Physical activity, min' wk $^{-1}$ & $93 \pm 238$ & $83 \pm 257$ & $52 \pm 160$ \\
Smoking, \% & & & $<.001$ \\
Never & 45.3 & 45.1 & 46.0 \\
Ex-smoker & 25.7 & 34.5 & 36.5 \\
Current, $<10$ a day & 6.4 & 4.8 & 3.9 \\
Current, 10-19 a day & 12.1 & 7.7 & 6.2 \\
Current, $\geq 20$ a day & 10.5 & 7.9 & 7.4 \\
\hline
\end{tabular}




\begin{tabular}{|c|c|c|c|c|}
\hline Social occupation class, $\%$ & & & & $<.001$ \\
\hline Professional/managerial & 34.6 & 35.1 & 30.0 & \\
\hline Skilled non-manual/manual & 42.0 & 42.1 & 42.3 & \\
\hline Semi/unskilled manual & 23.2 & 22.3 & 27.4 & \\
\hline Other (armed forces, etc.) & 0.4 & 0.4 & 0.3 & \\
\hline Longstanding illness, \% & 43.6 & 51.7 & 61.8 & $<.001$ \\
\hline Prevalent CVD, \% & 6.1 & 8.7 & 10.6 & $<.001$ \\
\hline
\end{tabular}


Table 2. Mean waist girth values in men and women according to body mass index and physical activity ${ }^{\mathrm{a}}$

\begin{tabular}{|c|c|c|c|c|c|c|}
\hline \multirow{2}{*}{$\begin{array}{l}\text { Leisure-time physical } \\
\text { activity }\end{array}$} & \multicolumn{3}{|c|}{ Men } & \multicolumn{3}{|c|}{ Women } \\
\hline & Normal BMI & Overweight & Obese & Normal BMI & Overweight & Obese \\
\hline $\begin{array}{l}\text { Meets guidelines, including } \\
\text { some vigorous activity }\end{array}$ & 87 & 96 & 109 & 76 & 85 & 99 \\
\hline $\begin{array}{l}\text { Meets guidelines, including } \\
\text { only moderate activity }\end{array}$ & 88 & 98 & 110 & 76 & 86 & 100 \\
\hline $\begin{array}{l}\text { Active, but not meeting } \\
\text { guidelines }\end{array}$ & 88 & 97 & 110 & 77 & 87 & 100 \\
\hline Inactive & 88 & 99 & 112 & 77 & 88 & 102 \\
\hline
\end{tabular}

${ }^{\mathrm{a}}$ Values are centimeters. Trained interviewers assessed physical activity and body mass index. Meeting prevailing guidelines was defined as at least 150 minutes per week of moderate-intensity physical activity, at least 75 minutes per week of vigorous-intensity physical activity, or equivalent combinations. Body mass index (BMI): normal is defined as $18.5-24.9 \mathrm{~kg} \cdot \mathrm{m}^{-2}$; overweight is defined as $25.0-29.9 \mathrm{~kg} \cdot \mathrm{m}^{-2}$; obese is defined as $\geq 30 \mathrm{~kg} \cdot \mathrm{m}^{-2}$. Trained and qualified nurses measured waist girth at the midpoint of the iliac crest and costal margin (lower rib). 
Table 3. Cox proportional hazard ratios for the associations between body mass index and cardiovascular disease mortality

\begin{tabular}{llll}
\hline Body mass index & Events/individuals & $\begin{array}{l}\text { Model 1, } \\
\text { HR }(95 \% \mathrm{CI})\end{array}$ & $\begin{array}{l}\text { Model 2, } \\
\text { HR }(95 \% \mathrm{CI})\end{array}$ \\
\hline Normal & $670 / 18401$ & 1.0 (Reference) & 1.0 \\
Overweight & $1015 / 25602$ & $0.96(0.87,1.06)$ & $0.97(0.87,1.07)$ \\
Obese & $617 / 15002$ & $1.28(1.15,1.43)$ & $1.23(1.10,1.37)$ \\
\hline
\end{tabular}

${ }^{a}$ Body mass index: normal is defined as $18.5-24.9 \mathrm{~kg} \cdot \mathrm{m}^{-2}$; overweight is defined as $25.0-29.9$ $\mathrm{kg} \cdot \mathrm{m}^{-2}$; obese is defined as $\geq 30 \mathrm{~kg} \cdot \mathrm{m}^{-2}(\mathrm{n}=59,005)$. Model 1 adjusted for age and sex. Model 2 adjusted for age, sex, smoking, physical activity, longstanding illness, social occupation class, and prevalent CVD. 
Table 4. Cox proportional hazard ratios for the associations between physical activity, body mass index, and cardiovascular disease mortality in adults age 40 years or older

\begin{tabular}{llll}
\hline \multirow{2}{*}{$\begin{array}{l}\text { Leisure-time physical } \\
\text { activity }\end{array}$} & \multicolumn{3}{c}{ Body mass index $^{\mathrm{a}}$} \\
\cline { 2 - 4 } & $\begin{array}{l}\text { Normal, } \\
\text { HR }(95 \% \mathrm{CI})\end{array}$ & $\begin{array}{l}\text { Overweight, } \\
\text { HR }(95 \% \mathrm{CI})\end{array}$ & $\begin{array}{l}\text { Obese, } \\
\text { HR }(95 \% \mathrm{CI})\end{array}$ \\
\hline Meets guidelines & $1.0($ Reference $)$ & $1.41(0.94,2.10)$ & $1.41(0.84,2.38)$ \\
\hline Does not meet guidelines & $1.41(0.94,2.12)$ & $1.34(0.92,1.95)$ & $1.84(1.21,2.81)$ \\
\hline None & $2.02(1.44,2.84)$ & $1.91(1.36,2.67)$ & $2.44(1.74,3.42)$ \\
\hline
\end{tabular}

There were 2,302 cardiovascular disease events in 59,005 individuals. Those with a body mass index $<18.5 \mathrm{~kg} \cdot \mathrm{m}^{-2}$ and those who died in the first two years of follow-up were removed to guard against reverse causation. Models adjusted for age, sex, smoking, total physical activity, longstanding illness, social occupation class, and prevalent CVD. Meeting physical activity guidelines was defined as at least 150 minutes per week of moderateintensity physical activity, at least 75 minutes per week of vigorous-intensity activity, or equivalent combinations. ${ }^{\mathrm{a}}$ Body mass index: normal is defined as $18.5-24.9 \mathrm{~kg} \cdot \mathrm{m}^{-2}$; overweight is defined as $25.0-29.9 \mathrm{~kg} \cdot \mathrm{m}^{-2}$; obese is defined as $\geq 30 \mathrm{~kg} \cdot \mathrm{m}^{-2}$. 
Table 5. Cox proportional hazard ratios for the associations between leisure-time physical activity, body mass index, and cardiovascular disease mortality in the physically active who reported taking part in vigorous-intensity activity and those who did not

\begin{tabular}{llll}
\hline \multirow{2}{*}{$\begin{array}{l}\text { Leisure-time physical } \\
\text { activity }\end{array}$} & \multicolumn{3}{c}{ Body mass index $^{\mathrm{b}}$} \\
\cline { 2 - 4 } & $\begin{array}{l}\text { Normal, } \\
\text { HR }(95 \% \mathrm{CI})\end{array}$ & $\begin{array}{l}\text { Overweight, } \\
\text { HR }(95 \% \mathrm{CI})\end{array}$ & $\begin{array}{l}\text { Obese, } \\
\text { HR }(95 \% \mathrm{CI})\end{array}$ \\
\hline Some vigorous & $1.0($ Ref $)$ & $1.85(0.92,3.70)$ & $1.25(0.50,3.12)$ \\
Moderate only & $1.45(0.70,3.01)$ & $1.70(0.86,3.37)$ & $2.52(1.15,2.53)$ \\
\hline
\end{tabular}

There were 130 cardiovascular disease events. ${ }^{\mathrm{a}} 6,799$ participants reported meeting physical activity guidelines, including some vigorous-intensity physical activity; 4,163 participants reported doing at least $150 \mathrm{~min} \cdot \mathrm{wk}^{-1}$ of leisure-time physical activity, including only moderate-intensity physical activities. Those with a body mass index $<18.5 \mathrm{~kg} \cdot \mathrm{m}^{-2}$ and those who died in the first two years of follow-up were removed to guard against reverse causation. Models adjusted for age, sex, smoking, total physical activity, longstanding illness, social occupation class, and prevalent CVD. ${ }^{b}$ Body mass index: normal is defined as 18.5-24.9 $\mathrm{kg} \cdot \mathrm{m}^{-2}$; overweight is defined as $25.0-29.9 \mathrm{~kg} \cdot \mathrm{m}^{-2}$; obese is defined as $\geq 30 \mathrm{~kg} \cdot \mathrm{m}^{-2}$. 


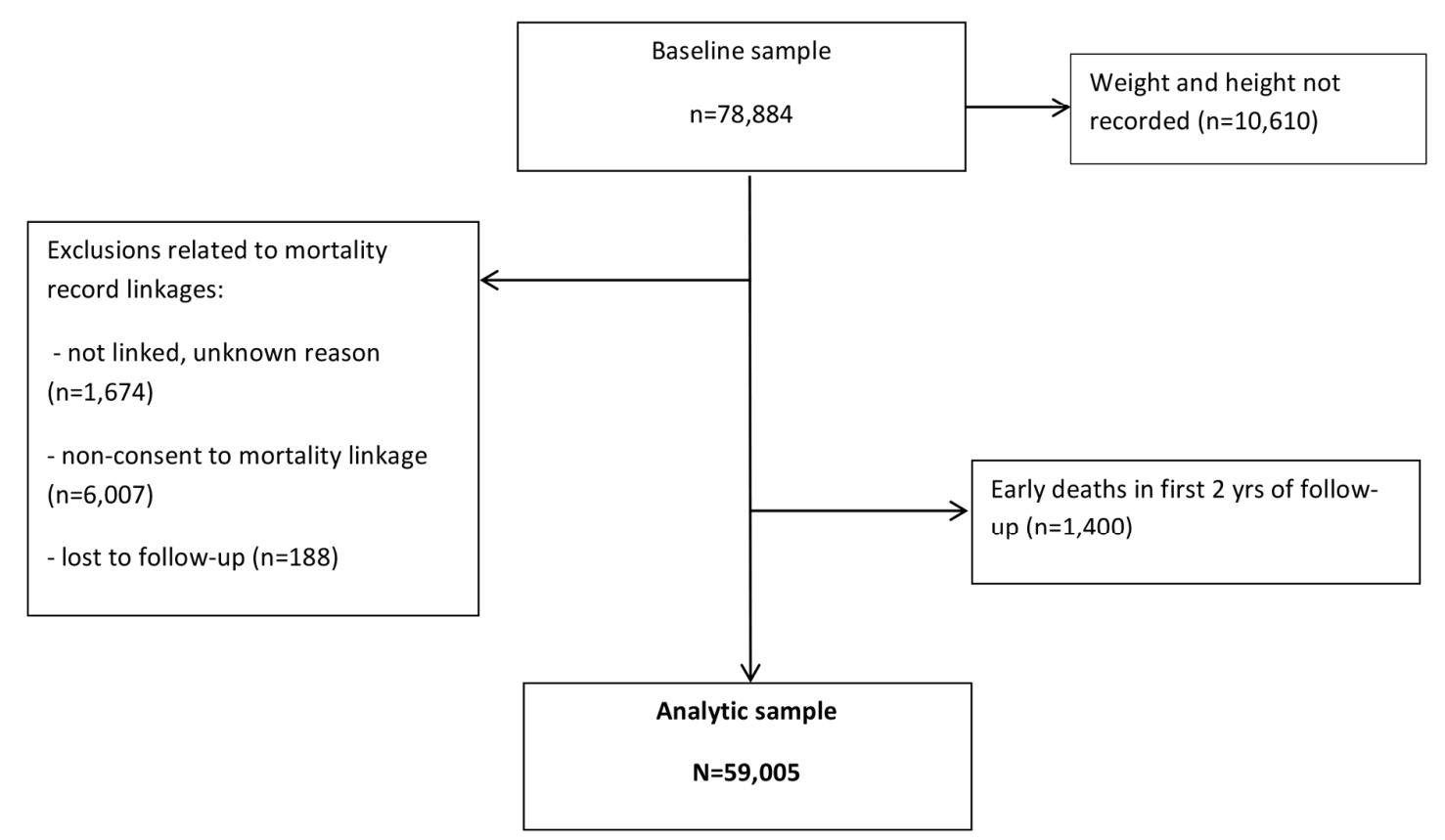

Supplemental Figure 1. Flow chart showing sample selection. 
Supplemental Table 1. Participants' physical activity levels according to prevailing physical activity guidelines ${ }^{\mathrm{a}}$

\begin{tabular}{lcc}
\hline \multirow{2}{*}{$\begin{array}{l}\text { Leisure-time physical } \\
\text { activity }\end{array}$} & Moderate- to vigorous- & Total, MET-hr· $\mathrm{wk}^{-1}$ \\
\cline { 2 - 3 } & intensity, $\mathrm{min} \cdot \mathrm{wk}^{-1}$ & \\
\hline Meets guidelines, including & $327 \pm 354$ & \\
some vigorous activity & & $48 \pm 47$ \\
Meets guidelines, including & $404 \pm 394$ & \\
only moderate activity & & $20 \pm 24$ \\
Active, but not meeting & $54 \pm 37$ & $14 \pm 22$ \\
guidelines & 0 & \\
Inactive & & \\
\hline
\end{tabular}

${ }^{\mathrm{a}}$ Trained interviewers assessed physical activity and meeting prevailing guidelines was defined as at least 150 minutes per week of moderate-intensity physical activity, at least 75 minutes per week of vigorous-intensity physical activity, or equivalent combinations (Haskell et al., Circulation, 2007, 116, 1081-93). A compendium was used to identify physical activity intensities according to metabolic equivalents (METs), where one MET represents resting energy expenditure (Ainsworth et al., Med Sci Sports Exerc, 2011, 43, 1575-81). Light activities were of 1.5-2.9 METs, moderate activities were of 3.0-5.9 METs, and vigorous activities were of $\geq 6.0$ METs. A MET-hour was computed by multiplying the MET score of an activity by the time (in hours). Total physical activity was computed by summing the MET-hours of all light, moderate, and vigorous activities. Compared with the inactive group, every other group is significantly different $(p<.001)$. 
Supplemental Table 2. Correlations between waist girth and body mass index in men and women according to physical activity level ${ }^{\mathrm{a}}$

\begin{tabular}{lcc}
\hline Leisure-time physical & Men & Women \\
activity & & .86 \\
\hline Meets guidelines & .85 & .85 \\
Active, but not meeting & .86 & \\
guidelines & & .85 \\
Inactive & .86 & \\
\hline
\end{tabular}

${ }^{\mathrm{a}}$ Values are partial correlations adjusted for age. Trained interviewers assessed physical activity and body mass index. Meeting prevailing guidelines was defined as at least 150 minutes per week of moderate-intensity physical activity, at least 75 minutes per week of vigorous-intensity physical activity, or equivalent combinations (Haskell et al., Circulation, $2007,116,1081-93)$. Body mass index: normal is defined as $18.5-24.9 \mathrm{~kg} \cdot \mathrm{m}^{-2}$; overweight is defined as $25.0-29.9 \mathrm{~kg} \cdot \mathrm{m}^{-2}$; obese is defined as $\geq 30 \mathrm{~kg} \cdot \mathrm{m}^{-2}$ (World Health Organization, Obesity and overweight. Fact sheet No 311. Geneva: WHO, 2016). Trained and qualified nurses measured waist girth at the midpoint of the iliac crest and costal margin (lower rib). 
Supplemental Table 3. Cox proportional hazard ratios for the associations between physical activity, body mass index, and cardiovascular disease mortality in men and women age 40 years or older ${ }^{\mathrm{a}}$

\begin{tabular}{|c|c|c|c|}
\hline \multirow{2}{*}{$\begin{array}{l}\text { Leisure-time physical } \\
\text { activity }\end{array}$} & \multicolumn{3}{|c|}{ Body mass index } \\
\hline & $\begin{array}{l}\text { Normal, } \\
\text { HR }(95 \% \text { CI) }\end{array}$ & $\begin{array}{l}\text { Overweight, } \\
\text { HR (95\% CI) }\end{array}$ & $\begin{array}{l}\text { Obese, } \\
\text { HR }(95 \% \text { CI })\end{array}$ \\
\hline \multicolumn{4}{|l|}{ Men } \\
\hline Meets guidelines & 1.0 (Reference) & $1.26(0.77,2.06)$ & $1.68(0.90,3.11)$ \\
\hline Does not meet guidelines & $1.17(0.68,2.01)$ & $1.42(0.89,2.27)$ & $1.99(1.17,3.39)$ \\
\hline None & $1.71(1.11,2.63)$ & $1.68(1.10,2.56)$ & $2.54(1.66,3.89)$ \\
\hline \multicolumn{4}{|l|}{ Women } \\
\hline Meets guidelines & 1.0 (Reference) & $1.63(0.82,3.23)$ & $0.91(0.32,2.54)$ \\
\hline Does not meet guidelines & $1.79(0.94,3.39)$ & $1.15(0.62,2.19)$ & $1.80(0.91,3.56)$ \\
\hline None & $2.54(1.45,4.44)$ & $2.40(1.38,4.19)$ & $2.57(1.46,4.50)$ \\
\hline
\end{tabular}

${ }^{\mathrm{a}}$ There were 1,242 cardiovascular disease events in 27,088 men and 1,060 cardiovascular disease events in 29,019 women. Those with a body mass index $<18.5 \mathrm{~kg} \cdot \mathrm{m}^{-2}$ and those who died in the first two years of follow-up were removed to guard against reverse causation. Models adjusted for age, sex, smoking, total physical activity, longstanding illness, social occupation class, and prevalent CVD. Meeting physical activity guidelines was defined as at least 150 minutes per week of moderate-intensity physical activity, at least 75 minutes per week of vigorous-intensity activity, or equivalent combinations. Body mass index: normal is defined as $18.5-24.9 \mathrm{~kg} \cdot \mathrm{m}^{-2}$; overweight is defined as $25.0-29.9 \mathrm{~kg} \cdot \mathrm{m}^{-2}$; obese is defined as $\geq$ $30 \mathrm{~kg} \cdot \mathrm{m}^{-2}$ 
Supplemental Table 4. Cox proportional hazard ratios for the associations between physical activity, body mass index, and cardiovascular disease mortality in non-smokers aged 40 years or older $^{\mathrm{a}}$

\begin{tabular}{llll}
\hline \multirow{2}{*}{$\begin{array}{l}\text { Leisure-time physical } \\
\text { activity }\end{array}$} & $\begin{array}{l}\text { Bormal, } \\
\text { HR }(95 \% \mathrm{CI})\end{array}$ & $\begin{array}{l}\text { Overweight, } \\
\text { HR }(95 \% \mathrm{CI})\end{array}$ & $\begin{array}{l}\text { Obese, } \\
\text { HR }(95 \% \mathrm{CI})\end{array}$ \\
\hline Meets guidelines & $1.0($ Reference $)$ & $1.70(0.86,3.37)$ & $1.84(0.75,4.51)$ \\
Does not meet guidelines & $1.78(0.89,3.54)$ & $1.41(0.73,2.71)$ & $1.66(0.79,3.48)$ \\
None & $2.28(1.27,4.10)$ & $2.11(1.18,3.78)$ & $2.94(1.64,5.30)$ \\
\hline
\end{tabular}

${ }^{\mathrm{a}}$ There were 802 cardiovascular disease events in 25,561 men and women who reported never smoking. Those with a body mass index $<18.5 \mathrm{~kg} \cdot \mathrm{m}^{-2}$ and those who died in the first two years of follow-up were removed to guard against reverse causation. Models adjusted for age, sex, total physical activity, longstanding illness, social occupation class, and prevalent CVD. Meeting physical activity guidelines was defined as at least 150 minutes per week of moderate-intensity physical activity, at least 75 minutes per week of vigorous-intensity activity, or equivalent combinations. Body mass index: normal is defined as 18.5-24.9 $\mathrm{kg} \cdot \mathrm{m}^{-2}$; overweight is defined as $25.0-29.9 \mathrm{~kg} \cdot \mathrm{m}^{-2}$; obese is defined as $\geq 30 \mathrm{~kg} \cdot \mathrm{m}^{-2}$. 